\title{
A 2.5D coupled FE-BE model for the prediction of railway induced vibrations
}

\author{
P. Galvín ${ }^{a, b}$, S. François ${ }^{a}$, M. Schevenels ${ }^{a}$, E. Bongini ${ }^{c}$, G. Degrande ${ }^{a}$, G. Lombaert $^{a}$ \\ ${ }^{a}$ Department of Civil Engineering, K.U.Leuven, Kasteelpark Arenberg 40, B-3001 Leuven, Belgium \\ ${ }^{b}$ Escuela Técnica Superior de Ingenieros, Universidad de Sevilla, Camino de los Descubrimientos s/n, E-41092 Sevilla, \\ Spain \\ ${ }^{c}$ SNCF, Direction de l'Innovation et de la Recherche, rue de Londres 45, 75379 Paris Cedex 8, France
}

\begin{abstract}
Ground vibrations induced by railway traffic at grade and in tunnels are often studied by means of two-and-half dimensional (2.5D) models that are based on a Fourier transform of the coordinate in the longitudinal direction of the track. In this paper, the need for $2.5 \mathrm{D}$ coupled finite element-boundary element models is demonstrated in two cases where the prediction of railway induced vibrations is considered. A recently proposed novel 2.5D methodology is used where the finite element method is combined with a boundary element method, based on a regularized boundary integral equation. In the formulation of the boundary integral equation, the Green's functions of a layered elastic halfspace are used, so that no discretization of the free surface or the layer interfaces is required. In the first case, two alternative models for a ballasted track on an embankment are compared. In the first model, the ballast and the embankment are modelled as a continuum using $2.5 \mathrm{D}$ solid elements, whereas a simplified beam representation is adopted in the second model. The free field vibrations predicted by both models are compared to those measured during a passage of the TGVA at a site in Reugny (France). A very large difference is found for the free field response of both models that is due to the fact that the deformation of the cross section of the embankment is disregarded in the simplified representation. In the second case, the track and free field response due to a harmonic load in a tunnel embedded in a layered halfspace are considered. A simplified methodology based on the use of the full space Green's function in the tunnel-soil interaction problem is investigated. It is shown that the rigorous finite element-boundary element method is required when the distance between the tunnel and the free surface and the layer interfaces of the halfspace is small compared to the wavelength in the soil.
\end{abstract}

Key words: 2.5D modelling, BEM-FEM coupling, dynamic soil-structure interaction, embankment, underground traffic

Email address: pedrogalvin@us.es (P. Galvín $\left.{ }^{a, b}\right)$ 


\section{Introduction}

The recent deployment of the high-speed train (HST) network in Europe, the USA, and Asia has stimulated the development of several numerical models for the prediction of railway induced vibrations. The most general framework is offered by the three-dimensional (3D) finite element (FE) method and 3D coupled finite element-boundary element (FE-BE) methods. These methods allow accounting for the full coupling between the track and the soil and can be used to study singular points in the track such as transition zones and switches. Furthermore, a time domain formulation offers the possibility to account for non-linear constitutive behaviour in the FE part of the model. Mohammadi and Karabalis [1] have presented a frequency domain FE-BE formulation where the railway track is modelled as a group of rigid sleepers resting on a viscoelastic halfspace. Andersen and Nielsen [2] have presented a FE-BE model in the frequency domain to investigate the free field response produced by vertical and horizontal moving loads on an embankment and the reduction of vibrations by means of barriers or soil improvement along the railway track. Celebi [3] has used a BE model to compute the transfer function between a point load on the track and the free field response and to study the mitigation of railway induced vibrations by open trenches. The track is represented by an equivalent homogeneous layer that represents a concrete slab or an asphalt layer over a base and frost protection layer. O'Brien and Rizos [4] have presented a direct time domain approach to study the transient response of a track-soil system due to the passage of trains where the sleepers are considered to be rigid and rails are coupled to the sleepers in the vertical direction only. Galvín and Domínguez [5, 6] and Galvín et al. [7] have presented a time domain formulation to study the ground motion due to a train

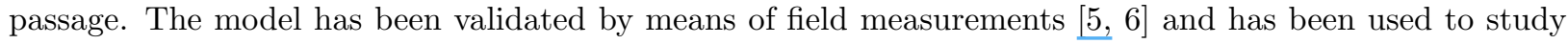
the influence of the ballast on a concrete underpass structure [5] and the vibration isolation by a floating slab track system [7]. The main disadvantage of 3D FE or FE-BE models is their very high computational cost.

As an alternative to full 3D models, so-called two-and-a-half dimensional (2.5D) models have been proposed for the prediction of railway induced vibrations. The basic assumption underlying the $2.5 \mathrm{D}$ methodology is that the geometry of the coupled track-soil system is invariant in the longitudinal direction of the track. This allows for a Fourier transform with respect to the coordinate along the track and leads to a solution in the frequency-wavenumber domain where the original 3D problem is replaced by a 2D problem for each wavenumber. The $2.5 \mathrm{D}$ methodology results in a considerable reduction of the time required to set up the model as well as the computation time. Aubry et al. [8] have applied a 2.5D procedure to study the response of an infinitely long beam, coupled to an elastic halfspace, due to a moving load. The methodology has been applied by Sheng et al. $\underline{[9,} \underline{10]}$ to an infinite layered beam model for the track, coupled to a layered halfspace. More recently, this model has been elaborated to account for dynamic train-track interaction $[11,12]$. In the model presented by Sheng et al. $[9,10,11,12]$, the tractions at the interface between the 
$[9, \underline{10}, \underline{11}, \underline{12}, \underline{17}, \underline{19}, \underline{20}]$. The transfer functions between the track and the free field are compared and subsequently used to predict free field vibrations during the passage of the TGVA at a site in Reugny (France). Predictions are compared to experimental results that have been obtained within the frame of a benchmark study organized by SNCF. In the second case, the track and free field response due to a harmonic load in a tunnel embedded in a layered halfspace are studied. The results of the FE-BE method are compared to those obtained from a simplified methodology presented by Hussein et al. [37] that allows for an approximate solution at reduced computational cost.

\section{The 2.5D coupled FE-BE model}

The dynamic interaction between a railway track and the underlying soil (figure 1a) or a tunnel and the surrounding soil (figure 1b) is a problem of dynamic soil-structure interaction. A domain decomposition method is used to solve the problem, where the subdomain $\Omega_{\mathrm{b}}$ represents the structure and the subdomain $\Omega_{\mathrm{s}}$ the soil. The soil-structure interaction problem is solved by enforcing continuity of displacements and equilibrium of stresses on the interface $\Sigma_{\mathrm{bs}}$ between both subdomains. It is assumed that the geometry of the track or the tunnel is invariant with respect to the coordinate $y$ in the longitudinal direction. The soil is modelled as a horizontally layered halfspace and, therefore, invariant with respect to the direction $\mathbf{e}_{y}$ as well. The dynamic soil-structure interaction problem is assumed to be linear and all equations are elaborated in the frequency domain. The dynamic equilibrium equation of the structure is discretized by means of $2.5 \mathrm{D}$ finite elements.

(a)

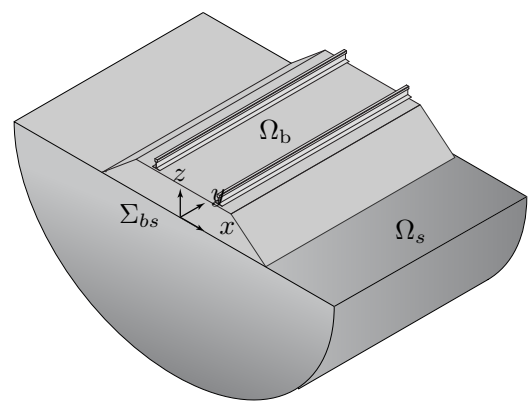

(b)

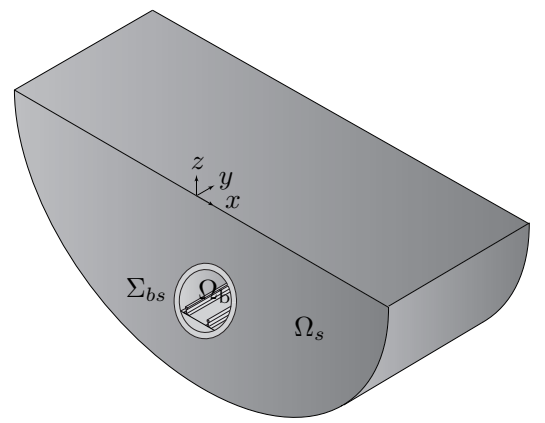

Figure 1: The 2.5D coupled FE-BE models: (a) a ballasted track at grade and (b) a tunnel in a halfspace

The equilibrium equation for the dynamic soil-structure interaction problem is formulated in a variational form. For any virtual displacement field $\mathbf{v}_{\mathrm{b}}$ imposed on the structure $\Omega_{\mathrm{b}}$, the sum of the virtual work of the internal and the inertial forces is equal to the virtual work of the external loads:

$$
-\omega^{2} \int_{\Omega_{\mathrm{b}}} \mathbf{v}_{\mathrm{b}} \cdot \rho_{\mathrm{b}} \mathbf{u}_{\mathrm{b}} d \Omega+\int_{\Omega_{\mathrm{b}}} \boldsymbol{\epsilon}_{\mathrm{b}}\left(\mathbf{v}_{\mathrm{b}}\right): \boldsymbol{\sigma}_{\mathrm{b}}\left(\mathbf{u}_{\mathrm{b}}\right) d \Omega=\int_{\Omega_{\mathrm{b}}} \mathbf{v}_{\mathrm{b}} \cdot \rho_{\mathrm{b}} \mathbf{b}_{\mathrm{b}} d \Omega+\int_{\Gamma_{\mathrm{b} \sigma}} \mathbf{v}_{\mathrm{b}} \cdot \overline{\mathbf{t}}_{\mathrm{b}}^{\mathbf{n}_{\mathrm{b}}} d \Gamma+\int_{\Sigma_{\mathrm{bs}}} \mathbf{v}_{\mathrm{b}} \cdot \mathbf{t}_{\mathrm{b}}^{\mathbf{n}_{\mathrm{b}}}\left(\mathbf{u}_{\mathrm{b}}\right) d \Gamma
$$


where $\mathbf{u}_{\mathrm{b}}$ is the displacement vector in the structure, $\rho_{\mathrm{b}} \mathbf{b}_{\mathrm{b}}$ denotes the body force in the domain $\Omega_{\mathrm{b}}$, and $\mathbf{t}_{\mathrm{b}}^{\mathbf{n}_{\mathrm{b}}}=\boldsymbol{\sigma}_{\mathrm{b}} \cdot \mathbf{n}_{\mathrm{b}}$ is the traction vector on a boundary with unit outward normal vector $\mathbf{n}_{\mathrm{b}}$. Tractions $\overline{\mathbf{t}}_{\mathrm{b}} \mathbf{n}_{\mathrm{b}}$ are imposed on the boundary $\Gamma_{\mathrm{b} \sigma}$.

Accounting for the equilibrium of stresses on the interface $\Sigma_{\mathrm{bs}}$ and using a finite element formulation for the interpolation of the displacement field with respect to the coordinates $x$ and $z$, equation (1) can be elaborated as follows $\underline{[22]}$ :

$$
\left[-\omega^{2} \mathbf{M}_{\mathrm{bb}}+\mathbf{K}_{\mathrm{bb}}^{0}-i k_{y} \mathbf{K}_{\mathrm{bb}}^{1}-k_{y}^{2} \mathbf{K}_{\mathrm{bb}}^{2}+i k_{y}^{3} \mathbf{K}_{\mathrm{bb}}^{3}+k_{y}^{4} \mathbf{K}_{\mathrm{bb}}^{4}+\mathbf{K}_{\mathrm{bb}}^{\mathrm{s}}\left(k_{y}, \omega\right)\right] \underline{\tilde{\mathbf{u}}}_{\mathrm{b}}\left(k_{y}, \omega\right)=\tilde{\mathbf{f}}_{\mathrm{b}}\left(k_{y}, \omega\right)
$$

where $\mathbf{K}_{\mathrm{bb}}^{0}, \mathbf{K}_{\mathrm{bb}}^{1}, \mathbf{K}_{\mathrm{bb}}^{2}, \mathbf{K}_{\mathrm{bb}}^{3}$ and $\mathbf{K}_{\mathrm{bb}}^{4}$ are the stiffness matrices, $\mathbf{M}_{\mathrm{bb}}$ is the mass matrix, $\tilde{\mathbf{f}}_{\mathrm{b}}\left(k_{y}, \omega\right)$ is the external load vector, and $\mathbf{K}_{\mathrm{bb}}^{\mathrm{s}}\left(k_{y}, \omega\right)$ represents the dynamic soil stiffness matrix. A tilde above a variable denotes its representation in the frequency-wavenumber domain. The finite element matrices $\mathbf{M}_{\mathrm{bb}}$ and $\mathbf{K}_{\mathrm{bb}}^{0}$ to $\mathbf{K}_{\mathrm{bb}}^{4}$ in equation (2) are independent of the wavenumber $k_{y}$ and the frequency $\omega$ and are only assembled once. Equation (2) is now further elaborated by dividing the finite element degrees of freedom $\tilde{\underline{u}}_{\mathrm{b}}\left(k_{y}, \omega\right)$ into internal degrees of freedom $\underline{\underline{\mathbf{u}}}_{\mathrm{b}_{1}}\left(k_{y}, \omega\right)$ and degrees of freedom $\underline{\mathbf{u}}_{\mathrm{b}_{2}}\left(k_{y}, \omega\right)$ on the soil-structure interface:

$$
\begin{aligned}
& \left(-\omega^{2}\left[\begin{array}{ll}
\mathbf{M}_{\mathrm{b}_{1} \mathrm{~b}_{1}} & \mathbf{M}_{\mathrm{b}_{1} \mathrm{~b}_{2}} \\
\mathbf{M}_{\mathrm{b}_{2} \mathrm{~b}_{1}} & \mathbf{M}_{\mathrm{b}_{2} \mathrm{~b}_{2}}
\end{array}\right]+\left[\begin{array}{cc}
\mathbf{K}_{\mathrm{b}_{1} \mathrm{~b}_{1}}^{0} & \mathbf{K}_{\mathrm{b}_{1} \mathrm{~b}_{2}}^{0} \\
\mathbf{K}_{\mathrm{b}_{2} \mathrm{~b}_{1}}^{0} & \mathbf{K}_{\mathrm{b}_{2} \mathrm{~b}_{2}}^{0}
\end{array}\right]-i k_{y}\left[\begin{array}{ll}
\mathbf{K}_{\mathrm{b}_{1} \mathrm{~b}_{1}}^{1} & \mathbf{K}_{\mathrm{b}_{1} \mathrm{~b}_{2}}^{1} \\
\mathbf{K}_{\mathrm{b}_{2} \mathrm{~b}_{1}}^{1} & \mathbf{K}_{\mathrm{b}_{2} \mathrm{~b}_{2}}^{1}
\end{array}\right]\right. \\
& -k_{y}^{2}\left[\begin{array}{ll}
\mathbf{K}_{\mathrm{b}_{1} \mathrm{~b}_{1}}^{2} & \mathbf{K}_{\mathrm{b}_{1} \mathrm{~b}_{2}}^{2} \\
\mathbf{K}_{\mathrm{b}_{2} \mathrm{~b}_{1}}^{2} & \mathbf{K}_{\mathrm{b}_{2} \mathrm{~b}_{2}}^{2}
\end{array}\right]+i k_{y}^{3}\left[\begin{array}{cc}
\mathbf{K}_{\mathrm{b}_{1} \mathrm{~b}_{1}}^{3} & \mathbf{K}_{\mathrm{b}_{1} \mathrm{~b}_{2}}^{3} \\
\mathbf{K}_{\mathrm{b}_{2} \mathrm{~b}_{1}}^{3} & \mathbf{K}_{\mathrm{b}_{2} \mathrm{~b}_{2}}^{3}
\end{array}\right]+k_{y}^{4}\left[\begin{array}{cc}
\mathbf{K}_{\mathrm{b}_{1} \mathrm{~b}_{1}}^{4} & \mathbf{K}_{\mathrm{b}_{1} \mathrm{~b}_{2}}^{4} \\
\mathbf{K}_{\mathrm{b}_{2} \mathrm{~b}_{1}}^{4} & \mathbf{K}_{\mathrm{b}_{2} \mathrm{~b}_{2}}^{4}
\end{array}\right] \\
& \left.+\left[\begin{array}{cc}
0 & 0 \\
0 & \mathbf{K}_{\mathrm{b}_{2} \mathrm{~b}_{2}}^{\mathrm{s}}\left(k_{y}, \omega\right)
\end{array}\right]\right)\left[\begin{array}{c}
\tilde{\mathbf{u}}_{\mathrm{b}_{1}}\left(k_{y}, \omega\right) \\
\tilde{\mathbf{u}}_{\mathrm{b}_{2}}\left(k_{y}, \omega\right)
\end{array}\right]=\left[\begin{array}{c}
\tilde{\tilde{\mathbf{f}}}_{\mathrm{b}_{1}}\left(k_{y}, \omega\right) \\
\tilde{\mathbf{f}}_{\mathrm{b}_{2}}\left(k_{y}, \omega\right)
\end{array}\right]
\end{aligned}
$$

The dynamic soil stiffness matrix $\tilde{\mathbf{K}}_{\mathrm{b}_{2} \mathrm{~b}_{2}}^{\mathrm{s}}\left(k_{y}, \omega\right)$ is written as:

$$
\tilde{\mathbf{K}}_{\mathrm{b}_{2} \mathrm{~b}_{2}}^{\mathrm{s}}\left(k_{y}, \omega\right)=\int_{\Sigma_{\mathrm{bs}}} \mathbf{N}_{\mathrm{b}_{2}}^{\mathrm{T}} \tilde{\mathbf{t}}_{\mathrm{s}}\left(\mathbf{N}_{\mathrm{b}_{2}}\right)\left(x, k_{y}, z, \omega\right) d \Gamma
$$

and computed by means of a $2.5 \mathrm{D}$ boundary element method. The boundary element mesh is chosen to match the finite element mesh on the soil-structure interface $\Sigma_{\mathrm{bs}}$. As a result, the boundary element interpolation functions $\mathbf{N}_{\mathrm{s}}(x, z)$ correspond to the finite element shape functions $\mathbf{N}_{\mathrm{b}_{2}}(x, z)$ on the soil-structure interface. This allows introducing the boundary element traction discretization in equation (4):

$$
\tilde{\mathbf{K}}_{\mathrm{b}_{2} \mathrm{~b}_{2}}^{\mathrm{s}}\left(k_{y}, \omega\right)=\left[\int_{\Sigma_{\mathrm{bs}}} \mathbf{N}_{\mathrm{b}_{2}}^{\mathrm{T}} \mathbf{N}_{\mathrm{b}_{2}} d \Gamma\right] \quad \tilde{\mathbf{t}}_{\mathrm{s}}\left(\mathbf{N}_{\mathrm{b}_{2}}\right)\left(k_{y}, \omega\right)=\tilde{\mathbf{T}}_{\mathrm{q}} \tilde{\mathbf{t}}_{\mathrm{s}}\left(\mathbf{N}_{\mathrm{b}_{2}}\right)\left(k_{y}, \omega\right)
$$

The transformation matrix $\mathbf{T}_{\mathrm{q}}=\int_{\Sigma_{\mathrm{bs}}} \mathbf{N}_{\mathrm{b}_{2}}^{\mathrm{T}} \mathbf{N}_{\mathrm{b}_{2}} d \Gamma$ in equation (5) is independent of wavenumber and frequency. The tractions $\tilde{\mathbf{t}}_{\mathrm{s}}\left(\mathbf{N}_{\mathrm{b}_{2}}\right)\left(k_{y}, \omega\right)$ are found by a $2.5 \mathrm{D}$ boundary element method, based on the integral equation that relates the displacements in the soil domain to the displacements and tractions on the soilstructure interface. The 2.5D boundary integral equation has been derived by Sheng et al. [29] from the 
$2.5 \mathrm{D}$ reciprocal theorem. In this paper, a regularized version $[22]$ of the $2.5 \mathrm{D}$ boundary integral equation is applied, leading to the following boundary element system of equations:

$$
\left[\tilde{\mathbf{T}}\left(k_{y}, \omega\right)+\mathbf{I}\right] \underline{\tilde{\mathbf{u}}}_{\mathrm{s}}\left(k_{y}, \omega\right)=\tilde{\mathbf{U}}\left(k_{y}, \omega\right) \tilde{\mathbf{t}}_{\mathbf{s}}\left(k_{y}, \omega\right)
$$

where $\tilde{\mathbf{U}}\left(k_{y}, \omega\right)$ and $\tilde{\mathbf{T}}\left(k_{y}, \omega\right)$ are fully populated unsymmetric boundary element system matrices. The unit matrix $\mathbf{I}$ corresponds to the integral-free term and is not present in the case of a bounded medium. The evaluation of the boundary element system matrices $\tilde{\mathbf{U}}\left(k_{y}, \omega\right)$ and $\tilde{\mathbf{T}}\left(k_{y}, \omega\right)$ in equation (6) requires the Green's displacements $\tilde{u}_{i j}^{\mathrm{G}}\left(x, k_{y}, z, \omega\right)$ and tractions $\tilde{t}_{i j}^{\mathrm{G}}\left(x, k_{y}, z, \omega\right)$ of the layered halfspace. These fundamental solutions are computed with the direct stiffness method $\underline{[13,} \underline{30]}$ using the MATLAB toolbox EDT 2.1 [31]. As the traction free surface of the halfspace is accounted for in these fundamental solutions, only the interface $\Sigma_{\mathrm{bs}}$ between the structure and the layered halfspace has to be discretized.

The tractions $\tilde{\mathbf{t}}_{\mathrm{s}}\left(\mathbf{N}_{\mathrm{b}_{2}}\right)\left(k_{y}, \omega\right)$ are found by solving the system of equations (6):

$$
\tilde{\mathbf{t}}_{\mathbf{s}}\left(\mathbf{N}_{\mathrm{b}_{2}}\right)\left(k_{y}, \omega\right)=\tilde{\mathbf{U}}^{-1}\left(k_{y}, \omega\right)\left(\tilde{\mathbf{T}}\left(k_{y}, \omega\right)+\mathbf{I}\right)
$$

An expression for the dynamic soil stiffness matrix $\tilde{\mathbf{K}}_{\mathrm{b}_{2} \mathrm{~b}_{2}}^{\mathrm{s}}\left(k_{y}, \omega\right)$ is found by introducing the solution (7) in equation (5):

$$
\tilde{\mathbf{K}}_{\mathrm{b}_{2} \mathrm{~b}_{2}}^{\mathrm{s}}\left(k_{y}, \omega\right)=\tilde{\mathbf{T}}_{\mathrm{q}} \tilde{\mathbf{U}}^{-1}\left(k_{y}, \omega\right)\left(\tilde{\mathbf{T}}\left(k_{y}, \omega\right)+\mathbf{I}\right)
$$

Once the equilibrium equation (3) for the dynamic soil-structure interaction problem has been solved, the integral representation theorem is applied to compute the radiated wave field from the tractions $\tilde{\mathbf{t}}_{\mathrm{s}}\left(k_{y}, \omega\right)$ and displacements $\underline{\underline{\mathbf{u}}}_{\mathbf{s}}\left(k_{y}, \omega\right)$ at the soil-structure interface:

$$
\tilde{\mathbf{u}}_{\mathrm{r}}\left(x, k_{y}, z, \omega\right)=\tilde{\mathbf{U}}_{\mathrm{r}}\left(x, k_{y}, z, \omega\right) \tilde{\mathbf{t}}_{\mathrm{s}}\left(k_{y}, \omega\right)-\tilde{\mathbf{T}}_{\mathrm{r}}\left(x, k_{y}, z, \omega\right) \tilde{\mathbf{u}}_{\mathrm{s}}\left(k_{y}, \omega\right)
$$

where the matrices $\tilde{\mathbf{U}}_{\mathrm{r}}\left(x, k_{y}, z, \omega\right)$ and $\tilde{\mathbf{T}}_{\mathrm{r}}\left(x, k_{y}, z, \omega\right)$ follow from the introduction of the boundary element discretization in the integral representation theorem and the vector $\underline{\underline{\mathbf{u}}}_{\mathrm{r}}\left(x, k_{y}, z, \omega\right)$ collects the displacement components at $n_{\mathrm{r}}$ receiver locations.

\section{A ballasted track on an embankment}

In this section, the proposed 2.5D FE-BE model is used to predict the track and free field vibrations at a site in Reugny (France) situated along the high speed railway line LGV Atlantique. The railway track in Reugny is a classical ballasted track, situated on top of an embankment [32]. The rails have a UIC60 cross section and are continuously welded. The rails are supported by rail pads and fixed with clips on twin block concrete sleepers [32] with a spacing of $d=0.60 \mathrm{~m}$. The concrete twin block sleepers have a total length $l_{\mathrm{sl}}=2.41 \mathrm{~m}$ and are composed of two tied concrete blocks with a length $l_{\mathrm{bl}}=0.84 \mathrm{~m}$, a width $b_{\mathrm{bl}}=0.29 \mathrm{~m}$ at the base, and a height $h_{\mathrm{bl}}=0.22 \mathrm{~m}$ under the rail. The total mass of the sleepers $m_{\mathrm{sl}}=250 \mathrm{~kg}$. The 
track is supported by a ballast layer with a thickness $h_{\mathrm{b}}$ of about $0.30 \mathrm{~m}$. The density of the ballast layer is situated in a range between $1400 \mathrm{~kg} / \mathrm{m}^{3}$ and $1700 \mathrm{~kg} / \mathrm{m}^{3}$. The embankment has a width of about $w_{\mathrm{e} 1}=6 \mathrm{~m}$ at the top supporting the railway track, a width of $w_{\mathrm{e} 2}=13 \mathrm{~m}$ at the soil's surface, and a height $h_{\mathrm{e}}=2 \mathrm{~m}$.

Two alternative track models are considered. For both models, the geometry of the coupled track-soil system is assumed to be invariant with respect to the longitudinal direction of the track, so that the $2.5 \mathrm{D}$ methodology can be applied. In the first model, the ballast and the embankment are modelled as an elastic continuum using 2.5D solid elements (figure 2). The second model is a simplified model where the ballast is represented by distributed springs and dampers while the embankment is modelled as an Euler-Bernoulli beam (figure 3). Similar simplified models of the ballast and the embankment have been frequently used in the literature $\underline{[9}, 10,11,12,17,19,20]$. In the following, the dynamic characteristics of the track and the soil that have been provided by the SNCF [32] within the frame of a benchmark study are used to define the parameters of both models. Next, the track receptance and free field mobility obtained by both models are compared. Finally, a comparison is made of the free field vibrations during the passage of the TGV Atlantique (TGVA).

\subsection{Track model 1}

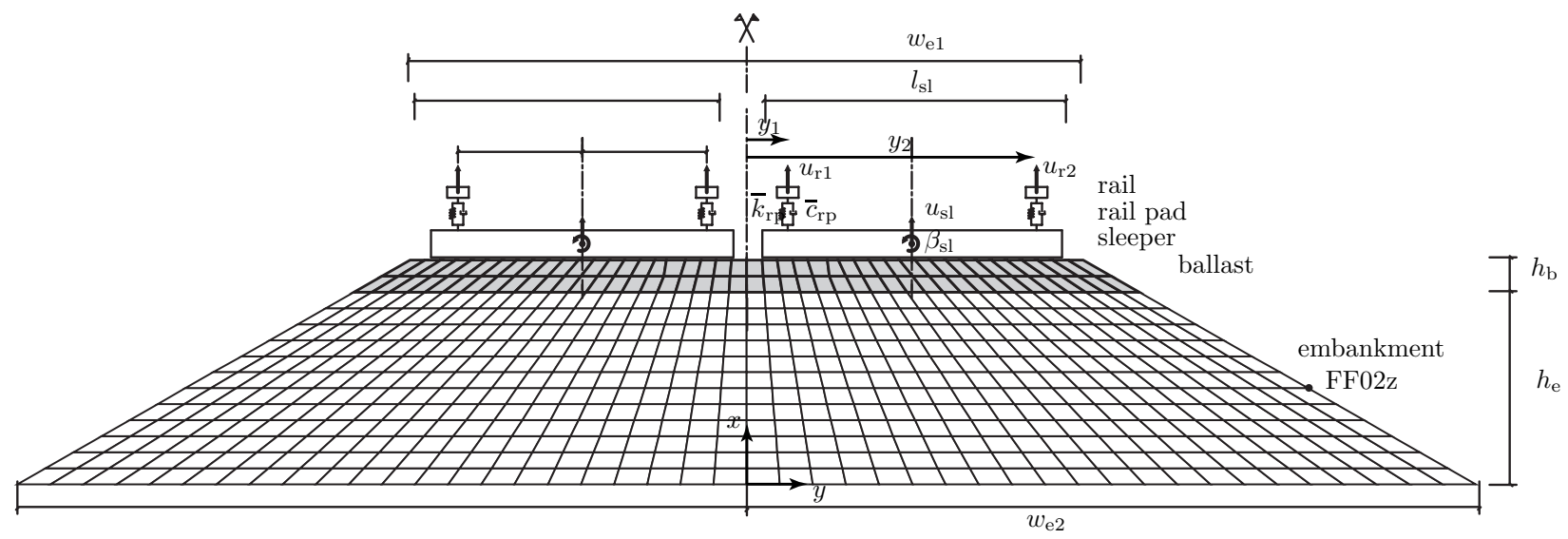

Figure 2: Cross section of model 1 of the ballasted track on the embankment.

Figure 2 shows the cross section of the first model with the mesh of the $2.5 \mathrm{D}$ solid elements that are used to model the ballast and the embankment. The rails are represented by Euler-Bernoulli beams with a bending stiffness $E_{\mathrm{r}} I_{\mathrm{r}}$ and a mass $\rho_{\mathrm{r}} A_{\mathrm{r}}$ per unit length. The rail displacements are denoted as $u_{\mathrm{r} 1}(y, t)$ and $u_{\mathrm{r} 2}(y, t)$. The positions of the rail are determined by $y_{1}=1.145 \mathrm{~m}$ and $y_{2}=2.580 \mathrm{~m}$, with $y_{2}-y_{1}$ equal to the track gauge $r_{\mathrm{d}}$. The UIC 60 rails have a bending stiffness $E_{\mathrm{r}} I_{\mathrm{r}}=6.45 \times 10^{6} \mathrm{~N} / \mathrm{m}^{2}$ and a mass per unit length $\rho_{\mathrm{r}} A_{\mathrm{r}}=60.34 \mathrm{~kg} / \mathrm{m}$ for each rail. The internal energy dissipation in the rail is modelled by a loss factor $\eta_{\mathrm{r}}=0.05$. The rail pads are modelled as continuous spring-damper connections. The rail pad 
stiffness $k_{\mathrm{rp}}$ of a single rail pad is used to calculate an equivalent stiffness $\bar{k}_{\mathrm{rp}}=k_{\mathrm{rp}} / d=130 \times 10^{6} \mathrm{~N} / \mathrm{m}^{2}$. A loss factor $\eta_{\mathrm{rp}}=0.23$ is used to account for internal energy dissipation in the rail pad.

The concrete sleepers are assumed to be rigid in the plane of the track cross section, so that the vertical sleeper displacements along the track are determined by the vertical displacement $u_{\mathrm{sl}}(y, t)$ and rotation $\beta_{\mathrm{sl}}(y, t)$ at the centre of gravity of the sleeper. The sleepers are modelled as a uniformly distributed mass $\bar{m}_{\mathrm{sl}}=m_{\mathrm{sl}} / d$ of $417 \mathrm{~kg} / \mathrm{m}$. The sleeper's rotational inertia $\rho_{\mathrm{sl}} \bar{I}_{\mathrm{sl}}=\rho_{\mathrm{sl}} I_{\mathrm{sl}} / d$ has been estimated as $298 \mathrm{kgm}^{2} / \mathrm{m}$ taking into account the excentric position of the two blocks.

The ballast bed is modelled as an elastic continuum, using $882.5 \mathrm{D}$ solid elements [22]. The Young's modulus of the ballast bed is computed from the given vertical ballast stiffness per sleeper $k_{\mathrm{b}}=180 \times 10^{6} \mathrm{~N} / \mathrm{m}$ taking into account the support area of the twin block sleeper $2 l_{\mathrm{bl}} b_{\mathrm{bl}}=0.48 \mathrm{~m}^{2}$. This results in a ballast stiffness $K_{\mathrm{b}}=370 \times 10^{6} \mathrm{~N} / \mathrm{m}^{3}$ or a Young's modulus $E_{\mathrm{b}}=K_{\mathrm{b}} h_{\mathrm{b}}=111 \times 10^{6} \mathrm{~N} / \mathrm{m}^{2}$. Additionally, a Poisson's ratio $\nu_{\mathrm{b}}=0.36$, a density $\rho_{\mathrm{b}}=1550 \mathrm{~kg} / \mathrm{m}^{3}$, and a loss factor $\eta_{\mathrm{b}}=1.00$ are assumed for the ballast layer. The embankment is modelled as an elastic continuum using $5282.5 \mathrm{D}$ solid elements. A Young's modulus $E_{\mathrm{e}}=170 \times 10^{6} \mathrm{~N} / \mathrm{m}^{2}$, Poisson's ratio $\nu_{\mathrm{e}}=0.36$, and a density $\rho_{\mathrm{e}}=1400 \mathrm{~kg} / \mathrm{m}^{3}$ are used for the embankment.

The soil is modelled as a horizontally layered elastic halfspace [32], with a single layer with a thickness of $2.0 \mathrm{~m}$ and a shear wave velocity $C_{\mathrm{s}}=211 \mathrm{~m} / \mathrm{s}$ on top of a halfspace with a shear wave velocity of $403 \mathrm{~m} / \mathrm{s}$. The density $\rho$ is equal to $1400 \mathrm{~kg} / \mathrm{m}^{3}$ for the top layer and equal to $2650 \mathrm{~kg} / \mathrm{m}^{3}$ for the underlying halfspace. The Poisson's ratio $\nu$ is 0.36 for the top layer and 0.16 for the halfspace. The material damping ratio $\beta$ in both deviatoric and volumetric deformation has a value of 0.05 and 0.06 for the top layer and the halfspace, respectively.

\subsection{Track model 2}

The cross section of model 2 is shown in figure 3. Compared to model 1 (figure 2), the rails, rail pads, sleeper, and underlying soil are modelled similarly, whereas a simplified model is used for the ballast and the embankment.

The ballast bed is now represented by a set of distributed linear springs and dampers. The smeared ballast stiffness $\bar{k}_{\mathrm{b}}$ is computed from the vertical spring stiffness $k_{\mathrm{b}}$ per sleeper $[\mathrm{N} / \mathrm{m}]$ as $k_{\mathrm{b}} / d$ and equal to $300 \times 10^{6} \mathrm{~N} / \mathrm{m}^{2}$. The loss factor $\eta_{\mathrm{b}}=1.00$. The equivalent ballast mass $\bar{m}_{\mathrm{b}}$ is computed from the ballast mass $m_{\mathrm{b}}$ situated under each sleeper as $m_{\mathrm{b}} / d$. The ballast mass $m_{\mathrm{b}}$ is estimated from the height $h_{\mathrm{b}}$ of the ballast layer and a width $w_{\mathrm{b} 1}=l_{\mathrm{sl}}$ and $w_{\mathrm{b} 2}=3 \mathrm{~m}$ at the top and the bottom of the ballast layer, respectively, as $m_{\mathrm{b}}=0.5 \rho_{\mathrm{b}} h_{\mathrm{b}}\left(w_{\mathrm{b} 1}+w_{\mathrm{b} 2}\right) b_{\mathrm{bl}}$. This leads to a value of $608 \mathrm{~kg} / \mathrm{m}$ for the equivalent ballast mass $\bar{m}_{\mathrm{b}}$.

The embankment is represented by an Euler-Bernoulli beam with a bending stiffness $E_{\mathrm{e}} I_{\mathrm{e}}$, a torsional rigidity $G_{\mathrm{e}} J_{\mathrm{e}}$, a rotational inertia $\rho_{\mathrm{e}} I_{p \mathrm{e}}$, and a mass $\rho_{\mathrm{e}} A_{\mathrm{e}}$ per unit length. This implies that the cross section of the embankment is now assumed to be rigid. The embankment has a Young's modulus $E_{\mathrm{e}}=$ 


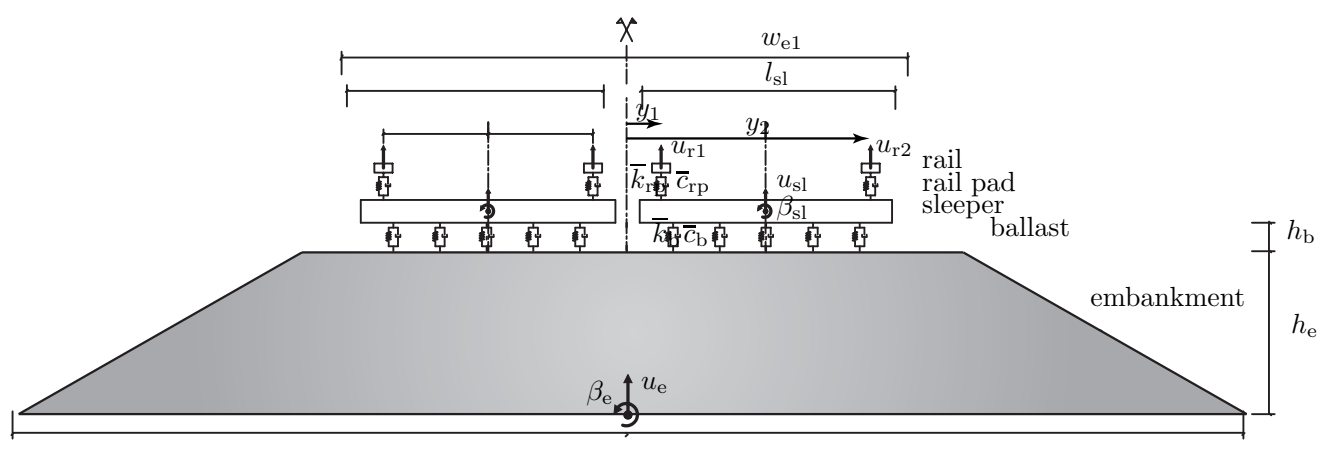

Figure 3: Cross section of model 2 of the ballasted track on the embankment.

$170 \times 10^{6} \mathrm{~N} / \mathrm{m}^{2}$, a shear modulus $G_{\mathrm{e}}=107 \times 10^{6} \mathrm{~N} / \mathrm{m}^{2}$, and a density $\rho_{\mathrm{e}}=1400 \mathrm{~kg} / \mathrm{m}^{3}$. Based on the dimensions of the cross section of the embankment, the following section characteristics have been computed: the area $A_{\mathrm{e}}=19 \mathrm{~m}^{2}$, the bending moment of inertia $I_{\mathrm{e}}=20.67 \mathrm{~m}^{4}$, the polar moment of inertia $I_{p \mathrm{e}}=182.96 \mathrm{~m}^{4}$, and the torsion constant $J_{\mathrm{e}}=22.03 \mathrm{~m}^{4}$.

At the interface between the embankment and the soil, relaxed boundary conditions are assumed, so that only continuity of the vertical displacements is imposed. Due to the assumption of a beam model, the vertical displacements $u_{\mathrm{s} z}(x, y, z=0, t)$ in the soil at the interface $\Sigma$ are determined by the vertical displacement $u_{\mathrm{e}}(y, t)$ and rotation $\beta_{\mathrm{e}}(y, t)$ at the centre of the interface.

It is expected that model 1 leads to more accurate results as it allows for a better approximation of the stress distribution at the interface between the embankment and the soil. Steenbergen and Metrikine [21] have shown that this is crucial for an accurate prediction of railway induced vibrations.

\subsection{Track receptance and free field mobility}

In the following, the track receptance and the free field mobility are compared for both models. The track receptance is computed from the solution of equation (3) that governs the dynamic track-soil interaction, considering an impulsive point load on both rails. The response of the outer rail at the point $y=0$ where the impulsive point load is applied is obtained subsequently by means of an inverse wavenumber domain transform. Figures 4a and 4b compare the modulus and phase of the track receptance for both models. As an additional reference, the track receptance has also been computed without taking into account the embankment in model 2. In this case, the interface between the ballast and the soil is assumed to be rigid over a width equal to the sleeper length $l_{\mathrm{sl}}=2.41 \mathrm{~m}$. This result is also shown in figure 4 .

The most pronounced difference between the results is found at frequencies below $100 \mathrm{~Hz}$. In this frequency range, the highest value for the track receptance is found for model 1 where the continuum model for the embankment allows accounting for the deformation of the cross section. In model 2, the deformation 
of the cross section of the embankment is disregarded and a substantially lower track receptance is found. A better agreement with model 1 is found when the embankment is disregarded in model 2 .

(a)

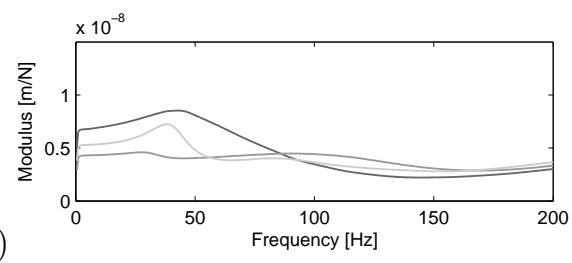

(b)

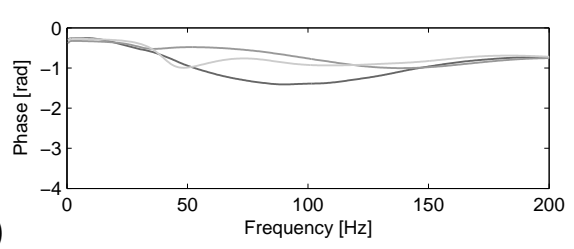

Figure 4: (a) Modulus and (b) phase of the track receptance computed by model 1 (dark grey line), model 2 (grey line), and model 2 without embankment (light grey line).

(a)
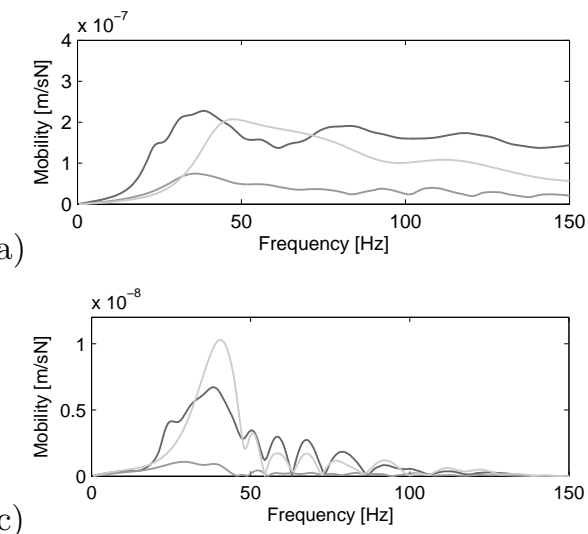

(b)
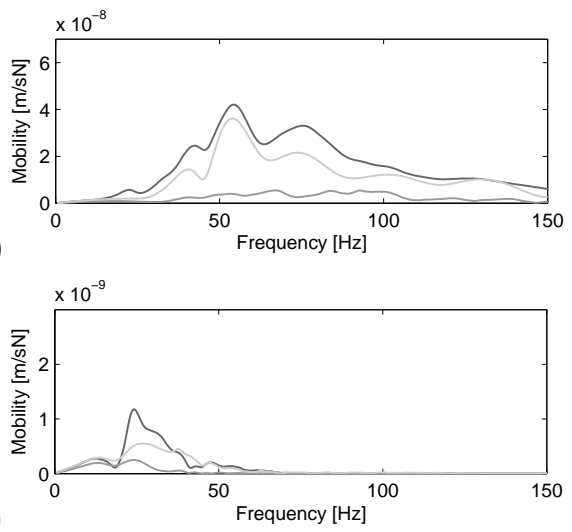

Figure 5: Free field mobility at (a) $2 \mathrm{~m}$, (b) $12 \mathrm{~m}$, (c) $32 \mathrm{~m}$, and (d) $72 \mathrm{~m}$ from the outer rail computed from model 1 (dark grey line), model 2 (grey line), and model 2 without embankment (light grey line).

Based on the solution of equation (3), the radiated wave field due to an impulsive point load on both rails is computed. The free field mobility is obtained as the inverse wavenumber domain transform of the free field velocity in the wavenumber-frequency domain. Figure 5 compares the free field mobility at a distance of $2 \mathrm{~m}, 12 \mathrm{~m}, 32 \mathrm{~m}$, and $72 \mathrm{~m}$ from rail 2 as computed with model 1 and model 2 . The point located at $2 \mathrm{~m}$ from the outer rail is situated on the embankment (figure 2). The free field mobility for the case where the embankment is omitted in model 2 is shown as well.

A very large difference is found between the results of model 1 with the solid embankment model and model 2 where the embankment is represented by an Euler-Bernoulli beam. The assumption of an EulerBernoulli model for the embankment leads to high tractions near the edges of the embankment, whereas in the case of the solid embankment model, the tractions are distributed more smoothly along the interface. When the wavelength in the soil is very large compared to the width of the interface between the embankment and the soil, the influence of the traction distribution on the free field mobility is small. In the present case 
where $w_{\mathrm{e} 2}=13 \mathrm{~m}$ and the shear wave velocity in the top layer $C_{\mathrm{s}}=211 \mathrm{~m} / \mathrm{s}$, this is only true at very low frequencies. At higher frequencies, the wavelength in the soil is of the same order of magnitude, so that the free field mobility is sensitive to the differences in the traction distribution. The high values of the tractions near the edges of the embankment in model 2 lead to a substantial filtering effect and therefore a much smaller free field mobility.

Disregarding the embankment in model 2 and assuming a rigid interface between the ballast and the soil leads to a better agreement with model 1 , as the tractions are now distributed over a much smaller width of $2.41 \mathrm{~m}$ corresponding to the sleeper length. The remaining underestimation of the free field mobility at low frequencies is due to the fact that incorporating the ballast and embankment as elastic continua in model 1 lowers the cut on frequency of the waves in the soil. For a layer with a thickness $d$ that is built in at its base, the cut on frequencies are equal to $C_{\mathrm{s}} /(4 d)$ and $C_{\mathrm{p}} /(4 d)$. The presence of the embankment and the ballast on top of the relatively soft layer of soil that overlies the stiffer halfspace increases the thickness of the softer top layer and results in lower cut on frequencies.

\subsection{The free field vibrations due to the passage of a TGVA}

The free field response is now computed at a distance of $2 \mathrm{~m}, 12 \mathrm{~m}, 32 \mathrm{~m}$, and $72 \mathrm{~m}$ from the outer rail of the track for the passage of a TGVA at a speed of $255 \mathrm{~km} / \mathrm{h}$. Only model 1 and model 2 with embankment are considered to illustrate the effect of the embankment model on the free field vibrations due to a train passage. The predicted free field vibrations are compared to the free field velocity that has been measured by the SNCF within the frame of a benchmark study for numerical models of railway induced vibrations. In the predictions, both quasi-static excitation and dynamic excitation due to random track unevenness are taken into account [17]. The following power spectral density (PSD) function is assumed for the random track unevenness:

$$
\tilde{S}_{\mathrm{r} z z}\left(n_{y}\right)=\tilde{S}_{\mathrm{r} z z}\left(n_{y 0}\right)\left(\frac{n_{y}}{n_{y 0}}\right)^{-w}
$$

where $\tilde{S}_{\mathrm{r} z z}\left(n_{y 0}\right)$ is the reference value of the PSD at $n_{y 0}=1 /(2 \pi) \mathrm{m}^{-1}$ and $w$ is the exponent that determines how strong the PSD function decreases with increasing cyclic wavenumber $n_{y}$. The coefficients $\tilde{S}_{\mathrm{r} z z}\left(n_{y 0}\right)$ and $w$ have been determined by fitting the one-third octave band RMS values of the PSD function in equation (10) to experimental data. The experimental RMS values in the one-third octave bands between $31.5 \mathrm{~cm}$ and $2000 \mathrm{~cm}$ have been obtained by combining information from a measurement trolley and a measurement coach. The fit is performed by the solution of a non-linear least-squares problem, leading to values of $w=4.45$ and $\tilde{S}_{\mathrm{r} z z}\left(n_{y 0}\right)=1.67 \times 10^{-6} \mathrm{~m}^{3} / \mathrm{rad}$. The dynamic axle loads have been computed for a single sample of the track unevenness. The reader is referred to Lombaert and Degrande [19] for a more elaborate description of the procedure, as well as for a discussion of the variability between predictions for different samples of track unevenness. 
Table 1: Geometrical and inertial characteristics of the TGVA.

\begin{tabular}{|c|c|c|c|c|c|c|c|c|c|c|}
\hline & & $\begin{array}{c}\text { Axles } \\
{[-]}\end{array}$ & $\begin{array}{r}L_{\mathrm{t}} \\
{[\mathrm{m}]} \\
\end{array}$ & $\begin{array}{l}L_{\mathrm{b}} \\
{[\mathrm{m}]}\end{array}$ & $\begin{array}{l}L_{\mathrm{a}} \\
{[\mathrm{m}]}\end{array}$ & $\begin{array}{l}M_{\mathrm{c}} \\
{[\mathrm{kg}]} \\
\end{array}$ & $\begin{array}{c}J_{\mathrm{c}} \\
{\left[\mathrm{kgm}^{2}\right]}\end{array}$ & $\begin{array}{l}M_{\mathrm{b}} \\
{[\mathrm{kg}]}\end{array}$ & $\begin{array}{c}J_{\mathrm{b}} \\
{\left[\mathrm{kgm}^{2}\right]}\end{array}$ & $\begin{array}{l}M_{\mathrm{u}} \\
{[\mathrm{kg}]}\end{array}$ \\
\hline 2 & Traction cars & 4 & 22.15 & 14.00 & 3.00 & 55790 & $1.15 \times 10^{6}$ & 2380 & 1480 & 2048 \\
\hline 2 & Side car & 3 & 21.84 & 18.70 & 3.00 & 24000 & $1.48 \times 10^{3}$ & 3040 & 2680 & 2003 \\
\hline 4 & Central car & 2 & 18.70 & 18.70 & 3.00 & 24000 & $1.48 \times 10^{3}$ & 3040 & 2680 & 2003 \\
\hline
\end{tabular}

The dynamic axle loads are computed using a compliance formulation in a frame of reference that moves with the train [33]. This methodology allows accounting for dynamic train-track interaction and the fact that all axles are coupled through the track. In the compliance formulation, a simplified vehicle model (figure 6) is adopted for the train where the motion of the car body is disregarded. This model suffices for the computation of the dynamic axle loads as the primary and secondary suspensions effectively isolate the carriages from the track vibrations at frequencies higher than a few Hertz [34]. The vehicle model (figure 6) has 4 degrees of freedom: the vertical displacement and rotation at the centre of gravity of the bogie and the vertical displacements of the two wheelsets. The entire TGVA is modelled as a sequence of independent bogies, based on the data available for the carriage length $L_{\mathrm{t}}$, the distance $L_{\mathrm{b}}$ between the bogies, the bogie wheel base $L_{\mathrm{a}}$, the mass of the bogie $M_{\mathrm{b}}$, the pitching moment of inertia $J_{\mathrm{b}}$, the unsprung mass $M_{\mathrm{u}}$ of the wheelsets (table 1) and the stiffness and damping of the primary and secondary suspension of the traction cars and passenger cars (table 2).

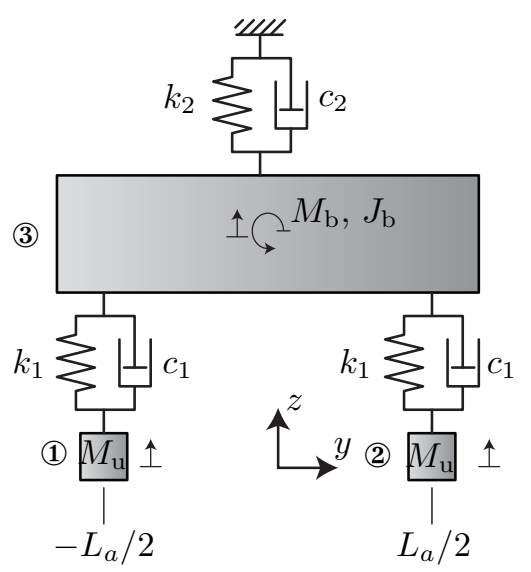

Figure 6: A 4 degree of freedom vehicle model 
Table 2: Dynamic characteristics of the primary and secondary suspension of the TGVA.

\begin{tabular}{ccccc}
\hline & $k_{1}$ & $c_{1}$ & $k_{2}$ & $c_{2}$ \\
& $\times 10^{6}[\mathrm{~N} / \mathrm{m}]$ & $\times 10^{3}[\mathrm{Ns} / \mathrm{m}]$ & $\times 10^{6}[\mathrm{~N} / \mathrm{m}]$ & $\times 10^{3}[\mathrm{Ns} / \mathrm{m}]$ \\
\hline Traction cars & 2.45 & 20 & 2.45 & 40 \\
Passenger car & 1.40 & 10 & 0.82 & 48 \\
\hline
\end{tabular}

(a)

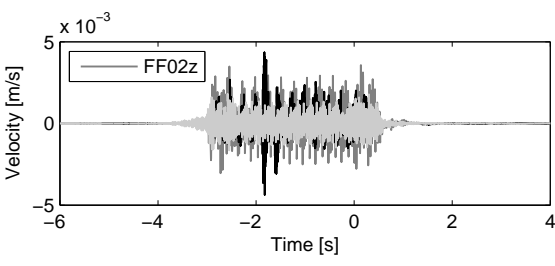

(b)
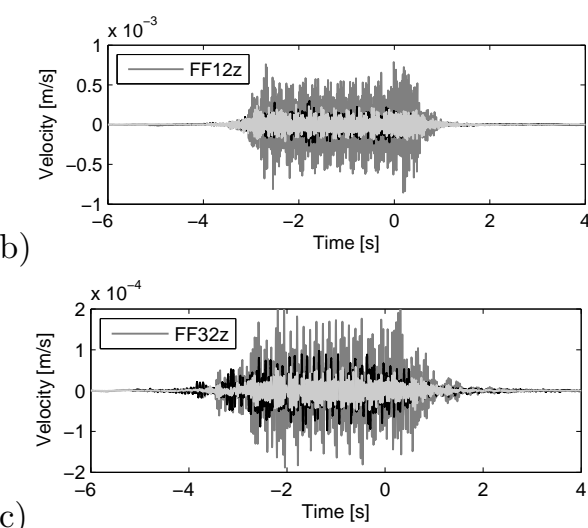

(c)

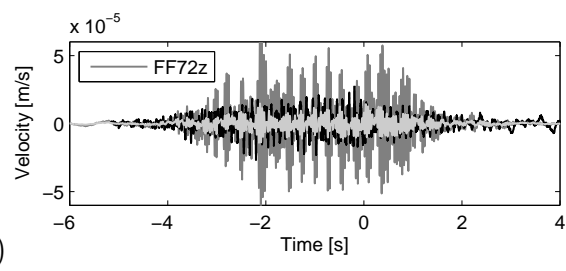

(e)

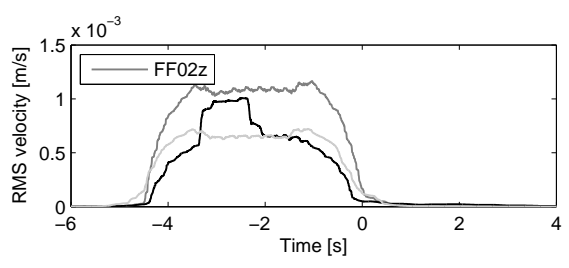

(f)
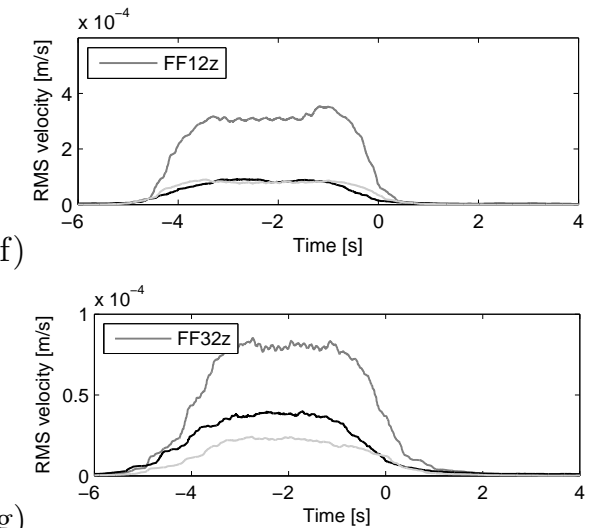

(g)

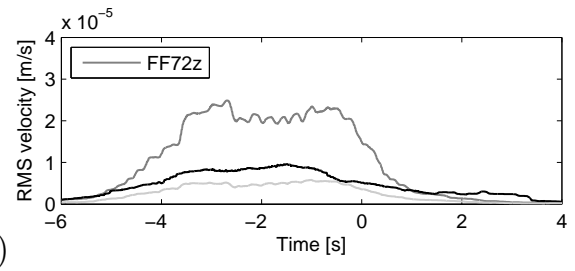

Figure 7: (a)-(d) Time history and (e)-(h) running RMS value of the measured (black line) and predicted free field velocity at $2 \mathrm{~m}, 12 \mathrm{~m}, 32 \mathrm{~m}$ and $72 \mathrm{~m}$ from the outer rail during the passage of the TGVA at a speed of $255 \mathrm{~km} / \mathrm{h}$ computed with model 1 (dark grey line) and model 2 (light grey line).

Figure 7 compares the time history and the running RMS value of the predicted free field velocity at $2 \mathrm{~m}, 12 \mathrm{~m}, 32 \mathrm{~m}$ and $72 \mathrm{~m}$ for the passage of the TGVA at a speed of $255 \mathrm{~km} / \mathrm{h}$ to the measured values. The running RMS value has been computed with a time window of $1 \mathrm{~s}$ as prescribed by the ISO 2631 standard [35]. The corresponding frequency content and one-third octave band spectra are shown in figure 8. The one-third octave band spectrum has been computed according to the German standard DIN 45672-2 [36] 
(a)
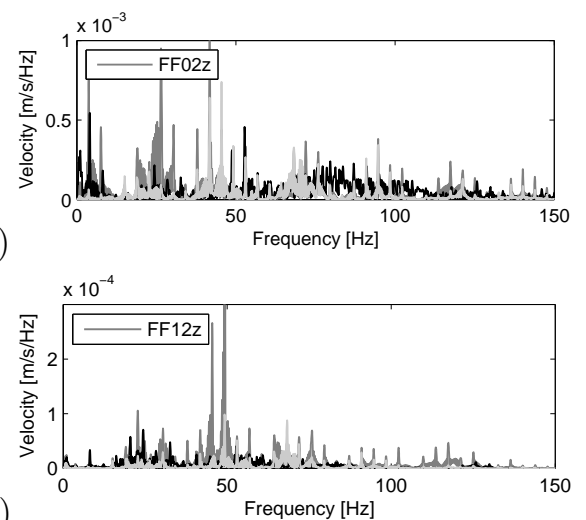

(b)

(c)
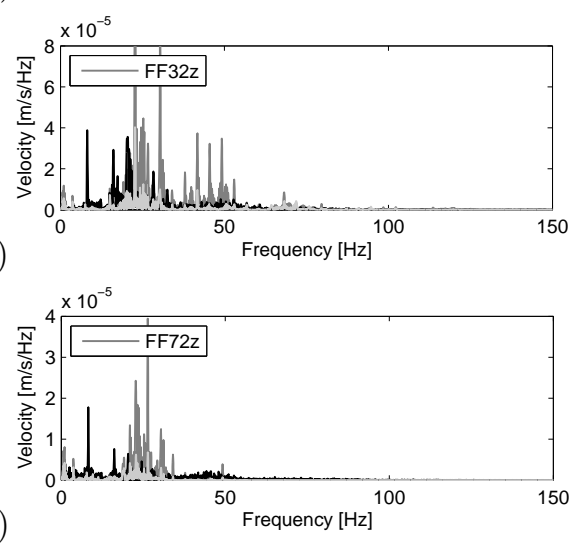

(e)

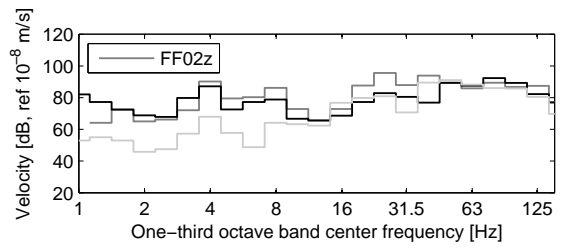

(f)

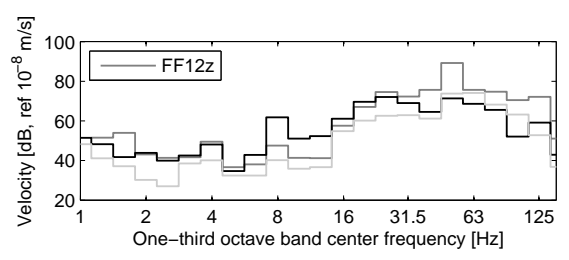

(g)

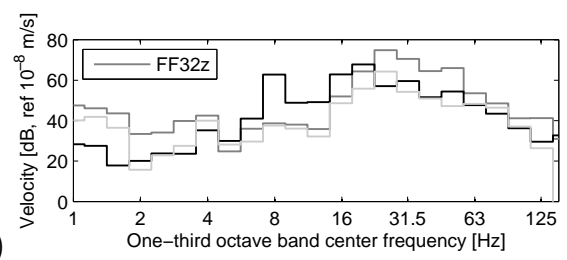

(h)

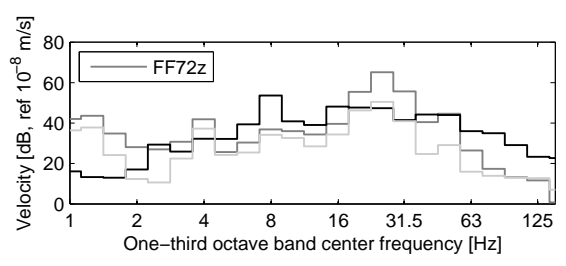

Figure 8: (a)-(d) Frequency content and (e)-(h) one-third octave band centre frequency of the measured (black line) and predicted free field velocity at $2 \mathrm{~m}, 12 \mathrm{~m}, 32 \mathrm{~m}$ and $72 \mathrm{~m}$ from the outer rail during the passage of the TGVA at a speed of $255 \mathrm{~km} / \mathrm{h}$ computed with model 1 (dark grey line) and model 2 (light grey line).

on a reference period $T_{2}$ during which the response is considered to be stationary. In the following, the two model predictions are compared to experimental results.

At $2 \mathrm{~m}$ from the outer rail (figures $7 \mathrm{a}$ and $7 \mathrm{e}$ ), a relatively good agreement is obtained between the measured and predicted time histories of the free field velocity. The duration of the signal as well as the peak value correspond relatively well, particularly for model 2 where the embankment is represented by a beam. Comparing the measured and predicted frequency content and one-third octave band spectra (figures $8 \mathrm{a}$ and $8 \mathrm{e}$ ) reveals, however, that model 2 considerably underestimates the response at low frequencies that is dominated by the quasi-static contribution. The correspondence in the low frequency range is much better for model 1. The overestimation of the running RMS value of the free field velocity by model 1 is due to an overestimation in the frequency range between $16 \mathrm{~Hz}$ and $63 \mathrm{~Hz}$.

At $12 \mathrm{~m}$ from the track (figures $7 \mathrm{~b}$ and $7 \mathrm{f}$ ), a significant overestimation of the measured free field velocity is observed for model 1 as well. A comparison of the predicted and experimental results in the frequency domain (figures $8 \mathrm{~b}$ and $8 \mathrm{f}$ ) shows that the overestimation is particularly large at frequencies above $31.5 \mathrm{~Hz}$, 
while at low frequencies a good agreement is observed for model 1. The overestimation at higher frequencies may be due to an overestimation of the dynamic axle loads, e.g. due to inaccurate track unevenness data.

With an increasing distance from the track, a strong attenuation of the free field velocity in the one-third octave bands above $31 \mathrm{~Hz}$ is observed. The stronger attenuation in the high frequency range is predominantly due to the effect of the material damping in the soil. The predicted attenuation, however, is much stronger than the observed attenuation, which is probably due to an overestimation of the material damping ratio $\beta$ in the soil.

Even when it is very hard to draw conclusions about the validity of the two embankment models based on a comparison with the measured response during a train passage, the results for the free field mobility clearly indicate that the beam model leads to a considerable overestimation of the stiffness of the embankment. The solid model for the embankment should therefore be preferred when studying vibrations induced by a train running on a track on embankment.

\section{A tunnel embedded in a layered halfspace}

In this section, the 2.5D methodology is used to study the behaviour of a tunnel embedded in a horizontally layered elastic halfspace. Furthermore, a method presented by Hussein et al. [37] is considered that allows for an approximate solution at reduced computational cost. It is investigated under which conditions the rigorous solution of the tunnel-soil interaction problem can be replaced by an approximate solution similar to the one proposed by Hussein et al. [37].

\subsection{The tunnel model}

A circular tunnel is considered (figure 9) with an internal radius $r_{\mathrm{i}}=2.75 \mathrm{~m}$ and a wall thickness $t=0.25 \mathrm{~m}$, resulting in an outer radius of $r_{\mathrm{e}}=3.0 \mathrm{~m}$. A tunnel invert is constructed to support the track. The material of the tunnel and tunnel invert is concrete with a Young's modulus $E_{\mathrm{t}}=35 \mathrm{GPa}$, a Poisson's ratio $\nu_{\mathrm{t}}=0.25$, a density $\rho_{\mathrm{t}}=2500 \mathrm{~kg} / \mathrm{m}^{3}$, and a hysteretic material damping ratio $\beta_{\mathrm{t}}=0.025$. The tunnel structure is modelled by means of $362.5 \mathrm{D}$ shell elements [22] in the circumferential direction (figure 9), while $142.5 \mathrm{D}$ solid elements [22] are used to model the tunnel invert.

The track is a floating slab track where the rails are supported by a concrete slab that is flexibly mounted on the tunnel invert. The rails have a UIC60 cross section and are supported each $d=0.60 \mathrm{~m}$ by rail pads. The track gauge $r_{\mathrm{d}}=1.435 \mathrm{~m}$. The rail pads are modelled by a continuous spring-damper connection with an equivalent stiffness $\bar{k}_{\mathrm{rp}}=k_{\mathrm{rp}} / d$ of $83.3 \times 10^{6} \mathrm{~N} / \mathrm{m}^{2}$ and a loss factor $\eta_{\mathrm{rp}}=0.3$. The concrete slab is represented by an Euler-Bernoulli beam with a bending stiffness $E_{\mathrm{sl}} I_{\mathrm{sl}}$ and a mass $\rho_{\mathrm{sl}} A_{\mathrm{sl}}$ per unit length. The vertical displacements of the beam are determined by the displacement $u_{\mathrm{sl}}(y, t)$ and rotation $\beta_{\mathrm{sl}}(y, t)$ at the centre of gravity. The height $h_{\mathrm{sl}}$ and width $l_{\mathrm{sl}}$ of the slab are equal to $0.55 \mathrm{~m}$ and $3.10 \mathrm{~m}$, respectively. 
This leads to a bending stiffness $E_{\mathrm{sl}} I_{\mathrm{sl}}=1500 \times 10^{6} \mathrm{Nm}^{2}$ and a mass per unit length $\rho_{\mathrm{sl}} A_{\mathrm{sl}}=3500 \mathrm{~kg} / \mathrm{m}$. A loss factor $\eta_{\mathrm{sl}}=0.05$ is used to model internal energy dissipation in the slab. The resilient material between the slab and the tunnel invert is assumed to act as a set of distributed, independent linear springs and dampers, with a vertical stiffness $K_{\mathrm{sm}}\left[\mathrm{N} / \mathrm{m}^{3}\right]$. The total vertical stiffness over the track width $l_{\mathrm{sl}}$ is denoted as $\bar{k}_{\mathrm{sm}}\left[\mathrm{N} / \mathrm{m}^{2}\right]$ and equal to $l_{\mathrm{sl}} K_{\mathrm{sm}}$. A value of $\bar{k}_{\mathrm{sm}}=13.82 \times 10^{6} \mathrm{~N} / \mathrm{m}^{2}$ has been chosen that results in a resonance frequency of $f=(2 \pi)^{-1} \sqrt{\bar{k}_{\mathrm{sm}} /\left(\rho_{\mathrm{sl}} A_{\mathrm{sl}}\right)}=10 \mathrm{~Hz}$ for the rigid slab on the resilient slab mat.

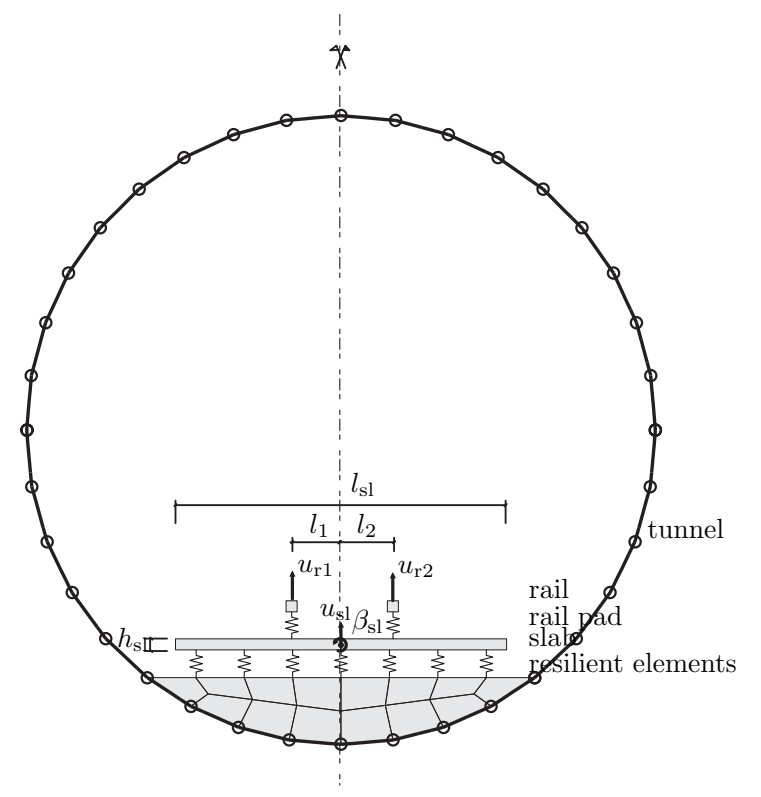

Figure 9: The discretization of the tunnel and the track.

The tunnel is embedded in a soil stratum that consists of a layer with a thickness of $2.0 \mathrm{~m}$ and a shear wave velocity of $100 \mathrm{~m} / \mathrm{s}$ on top of a halfspace with a shear wave velocity of $350 \mathrm{~m} / \mathrm{s}$. The density is equal to $1500 \mathrm{~kg} / \mathrm{m}^{3}$ for the top layer and equal to $1750 \mathrm{~kg} / \mathrm{m}^{3}$ for the underlying halfspace. In both soil layers, the Poisson's ratio equals 0.33 and the material damping ratio is equal to 0.025 for both deviatoric and volumetric deformation. In the following, two cases will be considered for the position of the tunnel. First, it is assumed that the centre of the tunnel is located at a depth of $20 \mathrm{~m}$ below the free surface (figure 10). In this case, the tunnel response is only marginally affected by the presence of the free surface and the top layer, so that the approximate solution proposed by Hussein et al. [37] is expected to yield relatively accurate results. Second, the centre of the tunnel is located at a depth of $5.5 \mathrm{~m}$ below the free surface, with the tunnel apex at only 0.5 from the layer interface and $3 \mathrm{~m}$ from the free surface. 


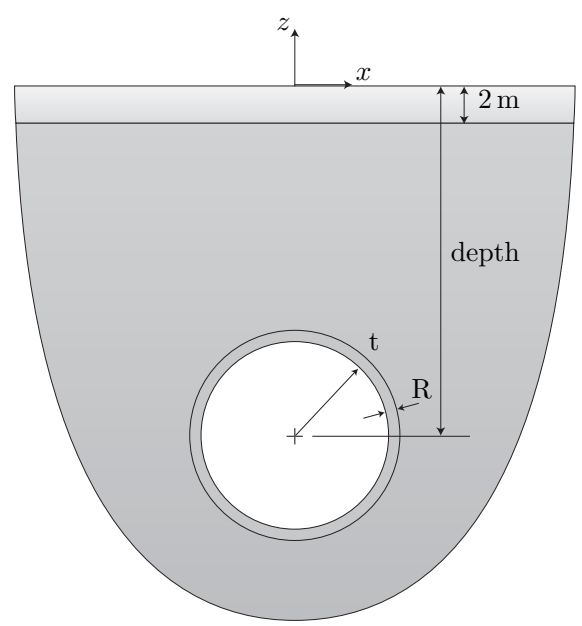

Figure 10: Cross section of the tunnel.

\subsection{The track receptance and track-soil transfer functions}

In the following, the track receptance and transfer functions between the track and the soil are computed by solving equation (3) that governs the dynamic interaction between the track, the tunnel and the soil. The load consists of an impulsive load on both rails.

Figures 11a and 11b show the modulus and phase of the track receptance and the corresponding response of the slab in the frequency range between $1 \mathrm{~Hz}$ and $100 \mathrm{~Hz}$. At frequencies below the resonance frequency of the slab mass on the stiffness of the resilient support, the rail and slab move in phase. At the resonance frequency, a peak is observed in the modulus of the response of the slab and the rail (figure 11a), while the phase equals $\pi / 2$. At higher frequencies, the rail is dynamically uncoupled from the slab and the response of the slab becomes much smaller.

(a)

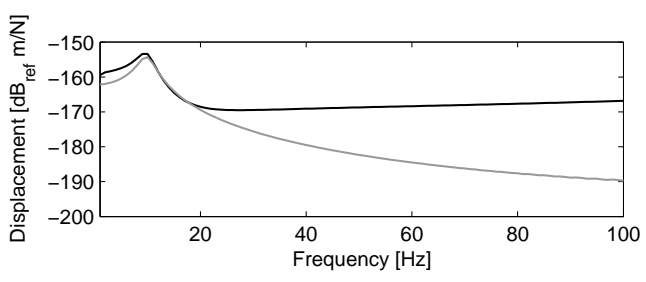

(b)

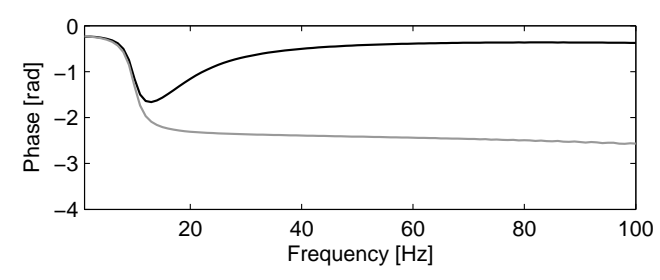

Figure 11: (a) Modulus and (b) phase of the track receptance (black line) and the corresponding response of the slab (grey line).

Figure 12a shows the displacement at a point $\{0,0,-10 \mathrm{~m}\}^{\mathrm{T}}$ located in the halfspace at a height of $10 \mathrm{~m}$ above the tunnel axis and a point $\{0,0,0\}^{\mathrm{T}}$ at the free surface, which is at a height of $20 \mathrm{~m}$ above the tunnel axis. The vertical displacements show clear oscillations as a function of the frequency due to interference between different types of waves that are radiated into the soil by the tunnel. Gupta et al. 
[23] have shown that for a tunnel embedded in a full space, the frequency spacing between the oscillations can be computed from the shear wave velocity $C_{\mathrm{s}}$, the longitudinal wave velocity $C_{\mathrm{p}}$ and the distance $r$ between the observation point and the source as $C_{\mathrm{s}} C_{\mathrm{p}} /\left(r\left(C_{\mathrm{p}}-C_{\mathrm{s}}\right)\right)$. In the present case of a layered halfspace, the interference pattern is more complicated, however, as it results from the interaction between Rayleigh waves and shear and longitudinal waves traveling in the different soil layers. Figure 12b shows the vertical displacement at two points $\{10 \mathrm{~m}, 0,0\}^{\mathrm{T}}$ and $\{20 \mathrm{~m}, 0,0\}^{\mathrm{T}}$ located at the free surface at a horizontal distance of $10 \mathrm{~m}$ and $20 \mathrm{~m}$ from the tunnel axis, respectively. The results in figures $12 \mathrm{a}$ and $12 \mathrm{~b}$ show that the largest response is not necessarily found at the smaller distance from the tunnel axis due to the interference and the directivity of the waves emitted by the tunnel.

(a)

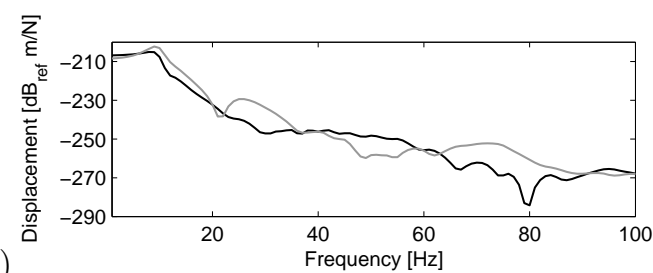

(b)

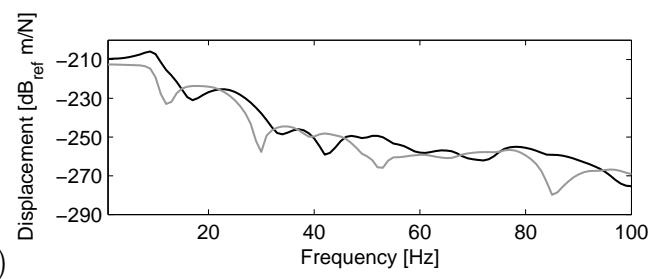

Figure 12: Vertical displacement in the soil at (a) two points $\{0,0,-10 \mathrm{~m}\}^{\mathrm{T}}$ (black line) and $\{0,0,0\}^{\mathrm{T}}$ (grey line) located above the tunnel axis and (b) two points $\{10 \mathrm{~m}, 0,0\}^{\mathrm{T}}$ (black line) and $\{20 \mathrm{~m}, 0,0\}^{\mathrm{T}}$ (grey line) at the free surface.

\subsection{Simplified methodology}

The proposed 2.5D methodology allows to rigorously account for the layered structure of horizontally stratified soils. This requires a computational cost which may be higher than for other models where approximate methods are used to account for the layered structure of the soil. Such an approach has recently been proposed by Hussein et al. [37] to extend the capabilities of the PiP model that originally predicts vibrations from underground traffic for a tunnel embedded in a full space $\underline{[26,27,} \underline{28]}$. First, the tunnel-soil interaction problem in equation (3) is solved considering the tunnel embedded in a homogeneous full space with the same properties as the layer in which the tunnel is located. This implies that the dynamic stiffness matrix of the soil in equation (5) is computed by solving the boundary element system of equations (6) in terms of the full space Green's functions. Second, the displacements and tractions at the tunnel-soil interface are used to compute the free field response according to equation (9) using the Green's function of a layered halfspace $[31,38]$. In this subsection, it is investigated under which conditions a similar approach can be followed to reduce the computational cost in the 2.5D framework.

First, the results presented in figures $12 \mathrm{a}$ and $12 \mathrm{~b}$ are recomputed with the approximate method, based on the solution of the dynamic tunnel-soil interaction problem in a homogeneous halfspace. Figure 13 compares the vertical displacement in the soil at $10 \mathrm{~m}$ and $20 \mathrm{~m}$ (the free surface) above the centre of the tunnel previously shown in figure $12 \mathrm{a}$ with the approximation based on the full space solution. It can be 
observed that a relatively good approximation of the solution has been obtained. A similar good agreement

(a)

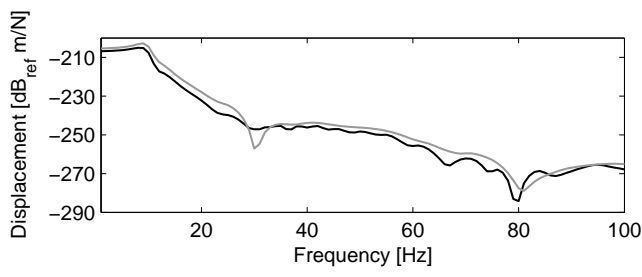

(b)

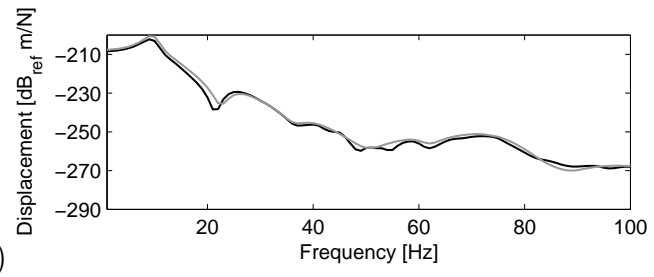

Figure 13: Vertical displacement in the soil at two points (a) $\{0,0,-10 \mathrm{~m}\}^{\mathrm{T}}$ and (b) $\{0,0,0\}^{\mathrm{T}}$ located above the tunnel axis computed with the original 2.5D methodology (black line) and the simplified 2.5D methodology (grey line).

is observed for the two points $\{10 \mathrm{~m}, 0,0\}^{\mathrm{T}}$ and $\{20,0,0\}^{\mathrm{T}}$ at the free surface (figure 14) for which the response has been previously shown in figure $12 \mathrm{~b}$.

In this case, the proposed simplified methodology allows for a good approximation of the response in the soil at a considerably reduced computational cost. It is clear, however, that the free surface and the layered structure of the soil can only be disregarded in the solution of the tunnel-soil interaction problem when the free surface and the layer interfaces are sufficiently far from the tunnel. In order to demonstrate the limitations of the proposed simplified methodology, a second case is considered where the centre of the tunnel is situated at a depth of $5.5 \mathrm{~m}$ below the free surface. In this case, the distance from the tunnel apex to the free surface is $2.5 \mathrm{~m}$ and the distance from the tunnel apex to layer interface is $0.5 \mathrm{~m}$.

(a)

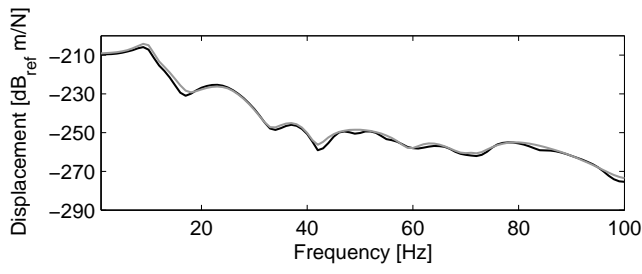

(b)

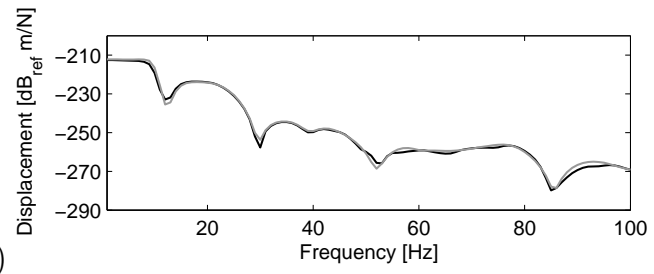

Figure 14: Vertical displacement in the soil at two points (a) $\{10 \mathrm{~m}, 0,0\}^{\mathrm{T}}$ and (b) $\{20 \mathrm{~m}, 0,0\}^{\mathrm{T}}$ located at the free surface computed with the original 2.5D methodology (black line) and the simplified 2.5D methodology (grey line).

Fig. 15 compares the vertical displacement in the soil at a height of $3.5 \mathrm{~m}$ above the centre of the tunnel (at the interface between the layer and the halfspace) and at a height of $5.5 \mathrm{~m}$ (the free surface) as computed with both methods. In this case, the agreement between both results is less good and differences higher than $10 \mathrm{~dB}$ are observed. An accurate solution of the tunnel-soil interaction problem is therefore only obtained by the original $2.5 \mathrm{D}$ methodology.

Figure 16 compares the vertical displacement at two points $\{10 \mathrm{~m}, 0,0\}^{\mathrm{T}}$ and $\{20,0,0\}^{\mathrm{T}}$ on the free surface. For these points, the simplified methodology results in a better approximation than for the points on top of the tunnel in figure 13. Based on a more extensive parametric study, it has been concluded that the 
(a)

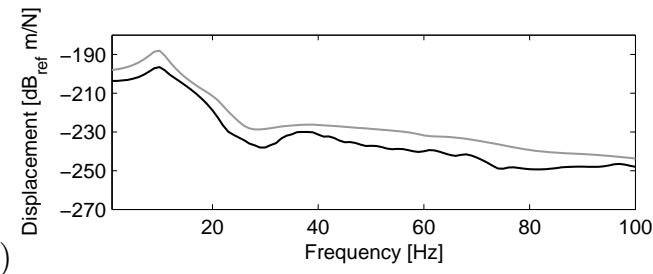

(b)

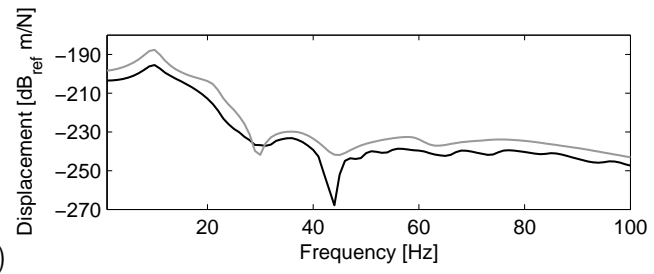

Figure 15: Vertical displacement in the soil at two points (a) $\{0,0,-2\}^{\mathrm{T}}$ and (b) $\{0,0,0\}^{\mathrm{T}}$ located above the tunnel axis computed with the original 2.5D methodology (black line) and the simplified 2.5D methodology (grey line) for a tunnel depth of $5.5 \mathrm{~m}$.

(a)

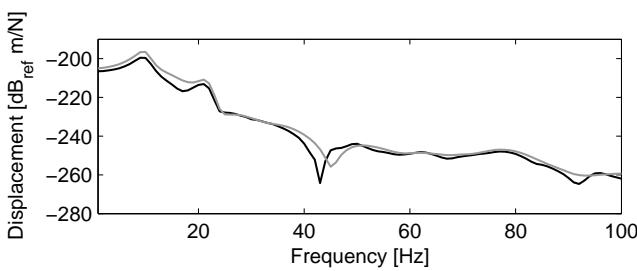

(b)

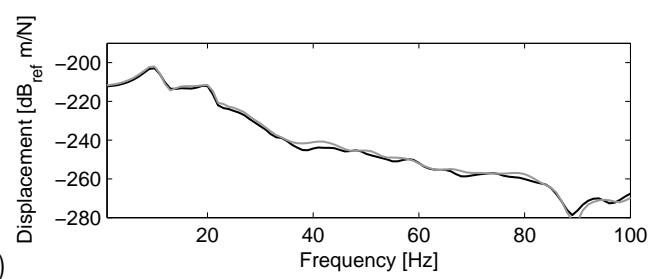

Figure 16: Vertical displacement in the soil at two points (a) $\{10 \mathrm{~m}, 0,0\}^{\mathrm{T}}$ and (b) $\{20 \mathrm{~m}, 0,0\}^{\mathrm{T}}$ located at the free surface computed with the original 2.5D methodology (black line) and the simplified 2.5D methodology (grey line) for a tunnel depth of $5.5 \mathrm{~m}$.

simplified methodology is valid when the distance between the tunnel and the surface of the halfspace spans a number of wavelengths so that the refracted wave does not significantly modify the tunnel-soil interaction problem. The same applies if the tunnel is located near an interface between two soil layers.

\section{Conclusions}

In this paper, the need for 2.5D coupled finite element-boundary element models is demonstrated in two cases where the prediction of railway induced vibrations is considered.

In the first case, two alternative models for a ballasted track on an embankment are considered. In the first model, 2.5D solid elements are used to model the ballast and the embankment as a continuum, whereas in the second model a simplified representation is used. The track receptance and free field mobility are found to differ considerably at higher frequencies where differences in the traction distribution at the interface between the embankment and the soil are resolved by the smaller wavelengths in the soil. A comparison of the predicted and measured free field velocity shows that the continuum model of the ballast and the embankment leads to a relatively good approximation at low frequencies where the quasi-static contribution to the response dominates. The less good agreement at high frequencies may be due to an overestimation of the dynamic axle loads.

In the second case, the response of a tunnel embedded in a layered halfspace is considered. The proposed 
2.5D methodology allows rigorously accounting for the layered structure, but may lead to relatively high computational cost. It has therefore been investigated under which conditions the proposed 2.5D methodology can be replaced by a simplified methodology based on the use of the full space Green's functions in the solution of the tunnel-soil interaction problem.

\section{Acknowledgements}

The first author would like to thank the Ministerio de Educación y Ciencia of Spain (JC2008-00136) and the Junta de Andalucía (IAC08-II-3343) for their financial support of his research stay at the Department of Civil Engineering of the K.U.Leuven.

The second and third author are holder of a Postdoctoral Fellowship of the Research Foundation Flanders (FWO-Vlaanderen). The financial support of FWO-Vlaanderen is kindly acknowledged.

\section{References}

[1] Mohammadi M, Karabalis DL. Dynamic 3-D soil-railway track interaction by BEM-FEM Earthquake Engineering and Structural Dynamics, 24 (1995) 1177-1193.

[2] Andersen L, Nielsen SRK. Reduction of ground vibration by means of barrier or soil improvement along a railway track Soil Dynamics and Earthquake Engineering, 25 (2005) 701-716.

[3] Celebi E. Three-dimensional modelling of train-track and sub-soil analysis for surface vibrations due to moving loads Applied Mathematics and Computation, 179 (2006) 209-230.

[4] O'Brien J, Rizos DC. A 3D BEM-FEM methodology for simulation of high speed train induced vibrations Soil Dynamics and Earthquake Engineering, 25 (2005) 289-301.

[5] Galvín P, Domínguez J. High-speed train-induced ground motion and interaction with structures Journal of Sound and Vibration, 307 (2007) 755-777.

[6] Galvín P, Domínguez J. Experimental and Numerical Analysis of Vibrations Induced by High-Speed Trains on the CórdobaMálaga Line Soil Dynamics and Earthquake Engineering, 29 (2009) 641-657.

[7] Galvín P, Romero A, Domínguez J. Vibrations induced by HST passage on ballast and non-ballast tracks Soil Dynamics and Earthquake Engineering, (2010) doi:10.1016/j.soildyn.2010.02.004.

[8] Aubry D, Clouteau D, Bonnet G. Modelling of wave propagation due to fixed or mobile dynamic sources. In N. Chouw and G. Schmid, editors, Proceedings of the International Workshop Wave 1994, Wave propagation and Reduction of Vibrations, (109-121) Ruhr University, Germany, 1994. A.A. Balkema, Rotterdam.

[9] Sheng X, Jones CJC, Petyt M. Ground vibration generated by a harmonic load acting on a railway track Journal of Sound and Vibration, 225 (1999) 3-28.

[10] Sheng X, Jones CJC, Petyt M. Ground vibration generated by a load moving along a railway track Journal of Sound and Vibration, 228 (1999) 129-156.

[11] Sheng X, Jones CJC, Thompson DJ. A comparison of a theoretical model for quasi-statically and dynamically induced environmental vibration from trains with measurements Journal of Sound and Vibration, 267 (2003) 621-635.

[12] Sheng X, Jones CJC, Thompson DJ. A theoretical model for ground vibration from trains generated by vertical track irregularities Journal of Sound and Vibration, 272 (2004) 937-965.

[13] Sheng X, Jones CJC, Thompson DJ. Prediction of ground vibration from trains using the wavenumber finite and boundary element methods Journal of Sound and Vibration, 293 (2006) 575-586. 
[14] Metrikine AV, Verichev SN, Blauwendraad J. Stability of a two-mass oscillator moving on a beam supported by a viscoelastic half-space International Journal of Solids and Structures, 42 (2005) 1187-1207.

[15] Metrikine AV, Popp K. Instability of vibrations of an oscillator moving along a beam on an elastic half-space European Journal of Mechanics, A/Solids 18 (1999) 331-349.

[16] Dieterman HA, Metrikine AV. The equivalent stiffness of a halfspace interacting with a beam. Critical velocities of a moving load along the beam European Journal of Mechanics, A/Solids 15 (1996) 67-90.

[17] Lombaert G, Degrande G, Kogut J, François S. The experimental validation of a numerical model for the prediction of railway induced vibrations Journal of Sound and Vibration 297 (2006) 512-535.

[18] Lombaert G, Degrande G, Clouteau D. Numerical modelling of free field traffic induced vibrations Soil Dynamics and Earthquake Engineering 19 (2000) 473-488.

[19] Lombaert G, Degrande G. Ground-borne vibration due to static and dynamic axle loads of InterCity and high-speed trains Journal of Sound and Vibration 319 (2009) 1036-1066.

[20] Lombaert G, Degrande G, Vanhauwere B, Vandeborght B, Franois S. The control of ground-borne vibrations from railway traffic by means of continuous floating slabs Journal of Sound and Vibration 297 (2006) 946-961.

[21] Steenbergen MJMM, Metrikine AV. The effect of the interface conditions on the dynamic response of a beam on a half-space to a moving load European Journal of Mechanics, A/Solids 26 (2007) 33-54.

[22] François S, Schevenels M, Galvín P, Lombaert G, Degrande G. A 2.5D coupled FE-BE methodolgy for the dynamic interaction between longitudinally invariant structures and a layered halfspace Computer Methods in Applied Mechanics and Engineering, (2010) doi: 10.1016/j.cma.2010.01.001.

[23] Gupta S, Hussein MFM, Degrande G, Hunt HEM, Clouteau D. A comparison of two numerical models for the prediction of vibrations from underground railway traffic Soil Dynamics and Earthquake Engineering, 27 (2007) 608-624.

[24] Gupta S, Liu WF, Degrande G, Lombaert G, Liu WN. Prediction of vibrations induced by underground railway traffic in Beijing Journal of Sound and Vibration, 310 (2008) 608-630.

[25] Clouteau D, Elhabre ML, Aubry D. Periodic BEM and FEM-BEM coupling: application to seismic behaviour of very long structures Computational Mechanics, 25 (2000) 567-577.

[26] Forrest JA, Hunt HEM. A three-dimensional tunnel model for calculation of train-induced ground vibration Journal of Sound and Vibration, 294 (2006) 678-705.

[27] Hussein MFM, Hunt HEM. A numerical model for calculating vibration from a railway tunnel embedded in a full-space. Journal of Sound and Vibration, 305 (2007) 401-431.

[28] Hussein MFM, Hunt HEM. A numerical model for calculating vibration due to a harmonic moving load on a floating-slab track with discontinuous slabs in an underground railway tunnel Journal of Sound and Vibration, 321 (2009) 363-374.

[29] Sheng X, Jones CJC, Thompson DJ. Modelling ground vibrations from railways using wavenumber finite- and boundaryelement methods Proceedings of the Royal Society, 461 (2005) 2043-2070.

[30] Tadeu AJB, Kausel E. Green's functions for a two-and-a-half dimensional elastodynamic problems ASCE Journal of Engineering Mechanics, 126 (2000) 1093-1097.

[31] Schevenels M, François S, Degrande G. EDT: An ElastoDynamics Toolbox for MATLAB Computers and Geosciences, 35 (2009) 1752-1754.

[32] Bongini E, Poisson F. Ground vibrations simulation cases parameters. Technical report, SNCF, France, 2009.

[33] Clouteau D, Lombaert G, Degrande G. Numerical modelling of traffic induced vibrations Meccanica, 36 (2001) $401-420$.

[34] Knothe K, Grassie SL. Modelling of railway track and vehicle/track interaction at high frequencies Vehicle Systems Dynamics, 22 (1993) 209-262.

[35] International Organization for Standardization. ISO 2631-2:1999: Mechanical vibration and shock - Evaluation of human exposure to whole-body vibration - Part 2: Vibration in buildings (1 to $80 \mathrm{~Hz}$ ), 1999. 
[36] Deutsches Institut für Normung. DIN 45672 Teil 2: Schwingungsmessungen in der Umgebung von Schienenverkehrswegen: Auswerteverfahren, 1995.

[37] Hussein MFM, Hunt HEM, Rikse L, Gupta S, Degrande G, Talbot JP, Francois S, Schevenels M. Using the PiP model for fast calculation of vibration from a railway tunnel in a multi-layered half-space 9th International Workshop on Railway Noise, Munich, Germany, 2007.

[38] Kausel E and Roesset JM. Stiffness matrices for layered soils Bulletin of the Seismological Society of America, 71 (1981) 1743-1761. 